\title{
Albizia lebbeck fruit pods as a substrate for the production of lignocellulolytic enzymes by Aspergillus niger
}

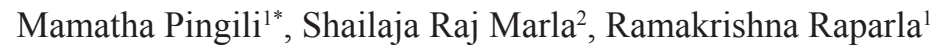 \\ ${ }^{1}$ Vaageswari Institute of Pharmaceutical Sciences, Karimnagar, India. \\ ${ }^{2}$ St. Francis College for Women, Begumpet, India.
}

\section{ARTICLE INFO \\ Article history: \\ Received on: March 05, 2020 \\ Accepted on: April 24, 2020 \\ Available online: May 26, 2020}

Key words:

Albizia lebbeck, LiP, endoglucanase, FPase, xylanase,

Aspergillus niger

\begin{abstract}
Aspergillus niger isolated from the soil was investigated for its capability to produce various lignocellulolytic enzymes, such as LiP, endoglucanase, FPase, xylanase by solid-state fermentation, using Albizia lebbeck fruit pods as a substrate. The chemical composition of the fruit pods was studied, and the production pattern of the enzymes was examined by growing the fungi for 25 days. The LiP activity was low, whereas a good production of endoglucanase, FPase, and xylanase enzymes was noted. A dye decolorization capacity of the $A$. niger was also studied with Congo red. Therefore, A. lebbeck fruit pods which are considered as waste and burnt off can be utilized for the production of holocellulolytic enzymes using A. niger.
\end{abstract}

\section{INTRODUCTION}

Lignocellulose is the most abundant raw material on the earth. It refers to plant dry matter (biomass) and is called lignocellulosic biomass. It is made up of cellulose, hemicellulose (together called holocellulose which are carbohydrate polymers), and lignin (aromatic polymer). The cellulose and hemicellulose are tightly bound to lignin.

Lignocellulose biomass is classified into three types: virgin biomass, waste biomass, and energy crops. All terrestrial plants, such as trees, bushes, and grass are included under virgin biomass. Waste biomass from agriculture, such as sugarcane bagasse, corn stover, and straw, and from forestry (paper and saw mills) is included under waste biomass. Energy crops are those with a high yield of lignocellulose biomass that serves as a raw material for the production of second-generation biofuels (switch grass) [1-3]. There are reports that lignocellulosic biomass has an immense potential for the sustainable production of chemicals and fuels. It has ample carbon-neutral renewable source which reduces

*Corresponding Author

Mamatha Pingili, Vaageswari Institute of Pharmaceutical Sciences, Karimnagar, India.E-mail: mamatharkrao@gmail.com
$\mathrm{CO}_{2}$ emissions and air pollution. It can be employed to produce biofuels, biomaterials, and biomolecules [4].

Fungi play a key role in degrading lignocellulose although bacterial degradation is also reported. Three groups of fungi are involved in lignocellulose degradation: soft-rot fungi, brownrot fungi, and white-rot fungi [5]. The soft-rot fungi attack the polysaccharide component of wood but are capable of degrading lignin to some extent [6]. Aspergillus sp. is an example of softrot fungi [7]. The genus Aspergillus is a group of filamentous fungi with a large number of species. Fourteen different groups of Aspergillus were identified [8]. There are eight groups of black Aspergillus identified (A. niger, A. tubingensis, A. heteromorphus, A. ellipticus, A. foetidus, A. carbonarius, A. japonicus, and $A$. aculeatus) [9]. Of these, $A$. niger and $A$. tubingensis are important for industrial applications. The products from many of these species have obtained a generally regarded as safe status which makes them to be used in food and feed applications. A myriad of enzymes produced by Aspergillus are of major importance to the food and feed industry. A good fermentation capabilities and high level of protein secretion make them ideal organisms for industrial applications [10].

Many lignocellulosic materials such as sugarcane bagasse, corn stover, bran, rice straw, and wheat straw have been studied as 
lignocellulolytic enzyme inducers. Along with conventional crop biomass, invasive weeds could be used as lignocellulosic enzyme inducers [11]. Enormous natural lignocellulosic sources are utilized worldwide, but still huge quantities of lignocellulosic raw materials are not still exploited [12]. Albizia lebbeck Benth., which is commonly called Indian siris or woman's tongue, is a deciduous tree whose parts have many medicinal values. The limited reports are available on the pods of the tree. They are not even graced by cattle as they contain saponins. The fruits fall on the ground, and they are burnt off, which leads to environmental pollution. The fruit pods of $A$. lebbeck are used as inducers for the production of lignocellulolytic enzymes by $A$. niger isolated from soil [13].

\section{MATERIALS AND METHODS}

\subsection{Plant Material}

The fruit pods for the current study were collected from Manakondur village, Karimnagar, Telangana, washed, shadedried cut into pieces, and made into coarse powder in a blender (1-2 mm).

\subsection{Organism}

The fungus $A$. niger was isolated from the soil in the laboratory [13].

\subsection{Solid State Fermentation of Fruit Pods of $A$. lebbeck}

About $5 \mathrm{~g}$ of the A. lebbeck fruit powder was moistened with $25 \mathrm{ml}$ of distilled water (ALW) and basal medium, (ALBM), separately, inoculated with two mycelial discs $(10 \mathrm{~mm})$ per flask, and incubated at $30^{\circ} \mathrm{C}$. A duplicate set of flasks was processed at 5, 10, 15, 20, and 25 days. Enzyme extraction [14] was done according to Arora et al. Sodium acetate buffer was added in each flask and kept on a shaker for 1 hour and filtered through a filter paper. The filtrate was then centrifuged at 10,000 rpm for 20 minutes, and the supernatant was used as the source of enzymes for assay and stored at $40^{\circ} \mathrm{C}$.

\subsection{Enzyme Assays}

Lignin peroxidase assay was carried out using Azure B [15], and the absorbance was read at $651 \mathrm{~nm}$. The xylanase assay was done according to the method of Bailey et al. [16], and endoglucanase and FPase activities were performed based on the methods proposed by Ghose et al. [17].

\subsection{Analytical Methods}

The estimation of various components in fruit pods was done by sequential fractionation $[18,19]$. About $1 \mathrm{~g}$ of substrate was suspended in $100 \mathrm{ml}$ of deionized water and heated in a water bath set at $100^{\circ} \mathrm{C}$ for 2 hours and filtered through a tared crucible. The residue was dried at $90^{\circ} \mathrm{C}$ until constant weight. The loss was considered as water soluble part. The dried residue was resuspended in $0.5 \mathrm{M} \mathrm{H}_{2} \mathrm{SO}_{4}$ and placed on a water bath maintained at $100^{\circ} \mathrm{C}$ for 2 hours and filtered, dried, and weighed. The loss was represented as hemicellulose. The residue was mixed with $72 \%$ $\mathrm{H}_{2} \mathrm{SO}_{4}(10 \mathrm{ml})$ maintained at $30^{\circ} \mathrm{C}$ for 1 hour, thereafter diluted

\begin{tabular}{|c|c|}
\hline \multicolumn{2}{|c|}{ Biochemical constituents of $A$. lebbeck fruit $(\mathrm{g} / \mathrm{Kg})$} \\
\hline Parameters & $\mathrm{g} / \mathrm{kg}$ \\
\hline Water solubles & 83 \\
\hline Hemicellulose & 260 \\
\hline Cellulose & 360 \\
\hline Lignin & 277 \\
\hline
\end{tabular}

up to $4 \% \mathrm{H}_{2} \mathrm{SO}_{4}$, and autoclaved at $121{ }^{\circ} \mathrm{C}$ for 40 minutes. The contents were then filtered, dried, and weighed, and the loss was considered as cellulose and residue as lignin.

\subsection{Congo Red Dye Transformation by $A$. niger}

The Congo red decolorization in solid media was assessed by visual disappearance of color from the plate [19]. A dye decolorization in liquid media was measured spectrophotometrically. The decolorization rate was determined according to the following formula:

Decolorization rate $(\%)=\frac{\left(A_{\mathrm{o}}-A_{\mathrm{I}}\right)}{A_{\mathrm{o}}} \times 100$

$A_{\mathrm{o}=}$ Dye absorbance of control

$A_{\mathrm{I}=}$ Dye absorbance after decolorization

\section{RESULTS AND DISCUSSION}

Fungi play an important role in lignocellulose degradation and are exploited for the production of the lignocellulose degrading enzymes on a large scale for their use in industry. They grow on a solid substrate with low moisture content (solidstate fermentation). A complex set of enzymes is involved in lignocellulose degradation such as ligninases, cellulases, and hemicellulases. In the present investigation, A. niger, a soft-rot fungus, was exploited for its ability to utilize lignocellulosic biomass of $A$. lebbeck fruit pods. The fungi were isolated from degrading fruit litter in a previous work in the laboratory and tested qualitatively for the release of various lignocellulolytic enzymes [13]. A. lebbeck fruit pods were collected, washed, shade dried, cut in to pieces, and ground to powder in a blender and sieved (1-2 $\mathrm{mm})$. A solid-state fermentation of the fruit substrate was carried out in two experimental setups by moistening fruit powder with ALW and ALB. SSF was preferred as it is the attractive means to produce enzymes at low investment and operating cost and requires simple equipment, and up on all, the fungi can penetrate deep in to substrate [20,21]. Biochemical constituents of $A$. lebbeck pods were done [22] and presented in Table 1.

Aspergillus niger was studied for its potential to produce lignocellulolytic enzymes such as LiP, endoglucanase, FPase, and xylanase. LiP breaks down lignin, whereas endoglucanase and FPase are involved in the hydrolysis of cellulose and xylanase in hemicellulose degradation. A time course study of SSF of $A$. lebbeck fruit powder (ALW and ALB in duplicates) was carried out for 25 days and analyzed for the enzymes at an interval of 5 days. 


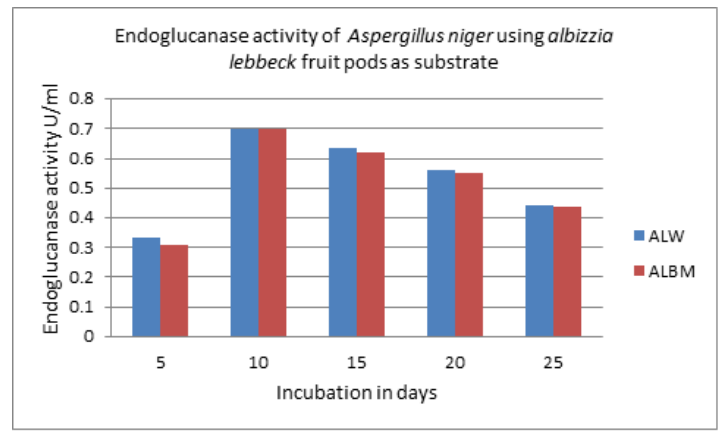

A

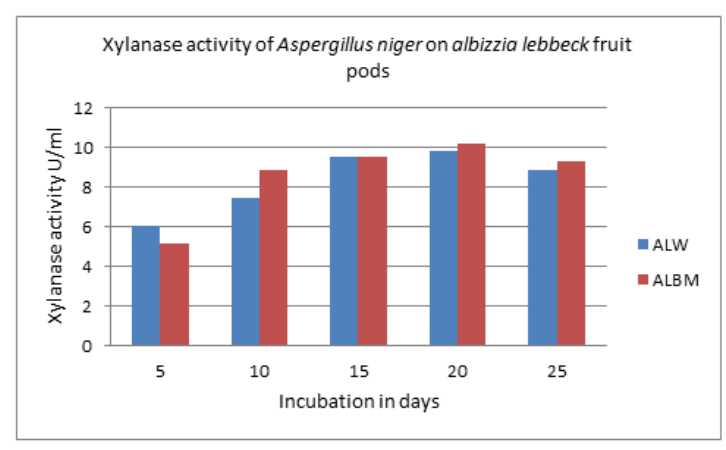

C

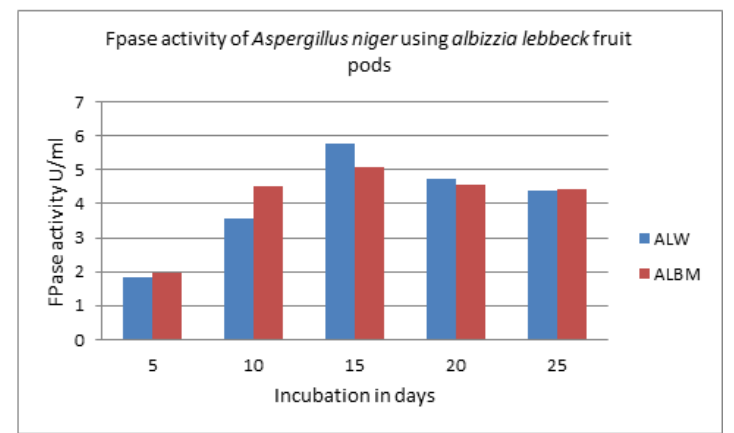

$\mathbf{B}$

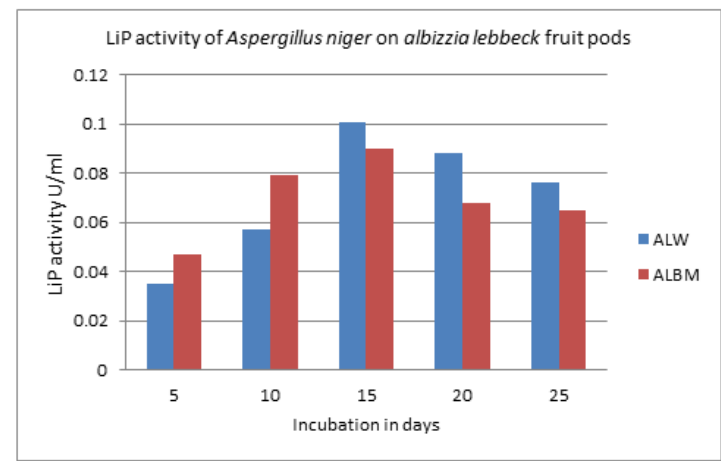

D

Figure 1: (A) Endoglucanase activity of $A$. niger on $A$. lebbeck fruit pods, (B) FPase activity of $A$. niger using $A$. lebbeck fruit pods, (C): Xylanase activity of $A$. niger using $A$. lebbeck fruit pods, (D): LiP activity of $A$. niger on $A$. lebbeck fruit pods.

Endoglucanase activity of diluted extract was highest on the 10th day of incubation in both ALW and ALB (0.7 and 0.698 $\mu \mathrm{mol} / \mathrm{minutes} / \mathrm{ml}$, respectively) and gradually decreased with incubation time. Both ALW and ALB exhibited the same pattern of endoglucanase activity during the 25-day fermentation (Fig. 1A). FPase activity was maximum on the 15 th day of incubation both in ALW (6.77 U/ml) and ALB (5.09 U/ml), and thereafter, it decreased gradually till 25 th day of incubation (Fig. 1B). It was noted that the xylanase activity of ALW increased till 15th day of incubation and that of ALB till 20th day of incubation with the maximum xylanase activity of $9.55 \mathrm{U} / \mathrm{ml}$ (15th day) for ALW and 10.15 U/ml (20th day) for ALB (Fig. 1C). Cellulolytic activities were studied with various other substrates. The studies on rice straw degradation with $A$. niger revealed $130 \mathrm{U} / \mathrm{gds}$ of cellulase activity [23]. Soybean hulls were used as a substrate, and $3.2 \mathrm{U} /$ $\mathrm{ml}$ of cellulase activity and $248.9 \mathrm{U} / \mathrm{ml}$ of xylanase activity were reported [24]. When Prosopis juliflora pods [25] were used, the cellulase activity of $1825.32 \mathrm{U} / 1$ and xylanase activity of $311.24 \mathrm{U} / 1$ was noted using Trichoderma reesei NCIM 1186. Endoglucanase activity of $3.42 \mathrm{U} / \mathrm{g}$ and Fpase activity of $1.77 \mathrm{U} / \mathrm{g}$ by Aspergillus niger was reported when coir waste was used as a substrate [26]. The studies on FPase and endoglucanase production by $A$. niger using wheat bran, rice bran, groundnut powder, and saw dust were reported [27]. FPase activity of 2.9, 2.09, and 1.62 FPU/g for wheat bran, groundnut fodder, and rice bran, respectively, was observed in the same study.. The highest titers of endoglucanase were recorded for wheat bran $(3.24 \mathrm{U} / \mathrm{g})$ and $1.36 \mathrm{U} / \mathrm{g}$ by groundnut fodder and $1.09 \mathrm{U} / \mathrm{g}$ by rice bran [27]. There are reports on xylanase activity of $A$. niger using sugarcane bagasse $\left(110 \mathrm{U} \mathrm{ml}^{-1}\right)$ and cassava bagasse (more than $160 \mathrm{U} \mathrm{ml}^{-1}$ ) [28]. It is arduous to compare the cellulolytic activities reported with other substrates as the authors demonstrated the activity in different units.

There are no reports on LiP activity by $A$. niger. In the present study, LiP activity was noted (Fig. 1D). Attempt to perform LiP activity was made as the fungi decolorized Azure B while qualitative screening was done in a previous study [13]. The LiP $(0.344 \mathrm{U} / \mathrm{ml}$ for ALW and $0.306 \mathrm{U} / \mathrm{ml}$ for ALB) production was very low when compared to LiP produced by white-rot fungi such as Phanerochaete chrysosporium which produced $1.80 \mathrm{U} / \mathrm{ml}$ using the same $A$. lebbeck fruit pod as a substrate [29]. The study on LiP production using Achras zapota [7] was reported to be $2,100 \mathrm{U} / \mathrm{ml}$. The degradation of Azure B in the qualitative studies may be attributed to other lignin degrading enzymes (manganese peroxidase, versatile peroxidase, or dye-decolorizing peroxidase), which are not covered under the purview of this study.

There is an increase in the water solubles with incubation period which indicates the degradation of lignocellulosic components into low molecular weight components. A loss in total organic matter (TOM), cellulose, hemicellulose, and lignin, and water solubles was analyzed according to the method of Datta [17] (Table 2). A comparison between TOM loss and loss in cellulose, hemicellulose, and lignin is shown in Figure 2. A strong correlation existed between TOM loss and lignin, cellulose, and hemicellulose loss. A strong positive correlation of 0.921 (ALW) and 0.964 (ALB) was noted between lignin loss and TOM loss. A correlation of 0.959 (ALW) and 0.863 (ALB) was observed between cellulose loss and TOM loss. Hemicellulose loss and TOM loss when compared had shown a correlation of 0.713 
Pingili, et al:: Albizia lebbeck fruit pods as a substrate for the production of lignocellulolytic enzymes by Aspergillus niger 2020;8(03):76-80 79

Table 2: Variations in A. lebbeck fruit composition during fermentation for 25 days.

\begin{tabular}{|c|c|c|c|c|c|c|c|}
\hline \multirow{2}{*}{ S. no } & & \multirow{2}{*}{ Parameters } & \multicolumn{5}{|c|}{ Days of incubation } \\
\hline & & & 5 & 10 & 15 & 20 & 25 \\
\hline \multirow{5}{*}{$\mathrm{a} 1$} & \multirow{5}{*}{ ALW } & TOM & 10 & 30 & 70 & 105 & 135 \\
\hline & & Water solubles & 65 & 55 & 65 & 60 & 80 \\
\hline & & Hemicellulose & 85 & 123 & 132 & 133 & 128 \\
\hline & & Cellulose & 100 & 120 & 230 & 250 & 270 \\
\hline & & Lignin loss & 45 & 60 & 135 & 150 & 145 \\
\hline \multirow{5}{*}{2} & \multirow{5}{*}{ ALB } & TOM & 10 & 15 & 50 & 90 & 125 \\
\hline & & Water solubles & 60 & 55 & 70 & 65 & 90 \\
\hline & & Hemicellulose & 79 & 95 & 110 & 115 & 121 \\
\hline & & Cellulose & 120 & 165 & 225 & 240 & 240 \\
\hline & & Lignin loss & 45 & 60 & 95 & 145 & 148 \\
\hline
\end{tabular}

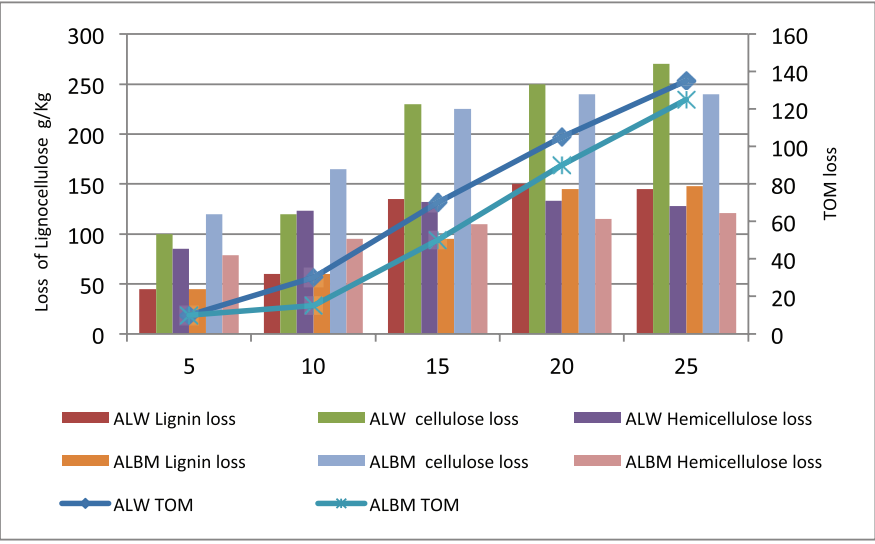

Figure 2: Comparison of TOM loss and lignin, cellulose, and hemicellulose loss.

(ALW) and 0.905 (ALB). It can be noted that lignin, cellulose, and hemicellulose loss contributed to TOM loss. Although LiP activity was low in A. niger, it degraded lignin efficiently, which indicates that other ligninolytic enzymes (MnP, $\mathrm{Vp}$, etc.) may be responsible for lignin degradation. On the whole, A. niger exhibited a good cellulase and xylanase activity using $A$. lebbeck fruit pods as a substrate.

The Congo red decolorization by A. niger was preliminarily evaluated in solid media. Decolorization was determined as the disappearance of the red color during fungal growth (Fig. 3A). The complete disappearance of the red color was achieved on the 6th day of fungal growth. Decolorization in liquid media was performed using Czapek-Dox medium. The total removal of dye was attained after 7 days of incubation (Fig. 3B). The decolorization capacity of the organism may be due to dye- decolorizing peroxidases, a new family of heme peroxidases. These enzymes have been demonstrated to perform lignin degradation [30].

\section{CONCLUSION}

Albizia lebbeck fruit pods used in the current study can be an attractive carbon source for enzyme production under solid-state fermentation by $A$. niger. Further, the pods can be subjected to pretreatment with acid or alkali and analyze the production of the enzymes.

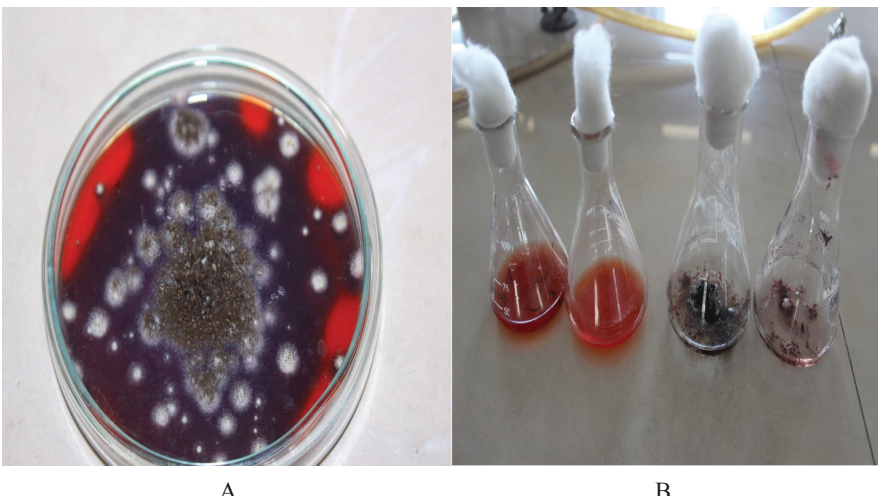

Figure 3: (A) Decolorization of Congo red on solid media and (B) liquid media.

\section{ACKNOWLEDGMENT}

The authors are grateful and thankful to the management of Vaageswari Group of Institutions for permitting to carry out the work in the institution.

\section{CONFLICT OF INTEREST}

The authors declare that they have no conflicts of interest.

\section{FINANCIAL SUPPORT}

None.

\section{REFERENCES}

1. Kirby R. Actinomycetes and lignin degradation. Adv Appl Microbiol 2005;58:125-68.

2. Gao H, Wang $\mathrm{Y}$, Zhang W, Wang W, Mu Z. Isolation, identification and application in lignin degradation of an ascomycete GHJ-4. Afr J Biotechno 2011;10(20):4166-74.

3. Amr A, Hanafy EJ, Hassan E, Abd-Elsalam HE, Elsayed E. Molecular characterization of two native Egyptian ligninolytic bacterial strains. J Appl Sci Res 2009;4:1291-6.

4. Maki-Arvela P, Anugwom I, Virtanen P, Sjoholm R, Mikkola JP. Dissolution of lignocellulosic materials and its constituents using ionic liquids - a review. Ind Crop Prod 2010;32:175-201. 
5. Ericksson LEL, Blanchette RA, Ander P. Microbial and enzymatic degradation of wood and wood components. Springer-Verlag, New York, NY, Berlin, Heidelberg, Germany,

6. Dix NJ, Webstar J. Fungal ecology. Chapman and Hall, London, UK, 1995.

7. Kumar AG, Sekaran G, Krishnamoorthy S, Solid state fermentation of Achras zapota lignocelluloses by phanerochaete chrysosporium. Bioresource Technol 2006;97:1521-8.

8. Raper KB, Thom C. A manual of the Aspergilli. Philadelphia, PA: Williams \& Wilkins company; 1945. pp 1-875.

9. Perenicova L, Benen JAE, Samson RA, Visser J. Evaluation of RFLP analysis of the classification of selected aspergilla. Mycol Res ; 101:810-4.

10. Davies, RW. Heterologous gene expression and protein secretion in Aspergillus. Prog Ind Microbiol ;29:527-60.

11. Adak A, Singh S, Lavanya AK, Sharma A, Nain L. Sustainable production of biofuels from weedy biomass and other unconventional lignocellulose wastes. Springer Int Publ AG 2018.

12. Sethi S, Datta A, Gupta BL, Gupta S. Optimization of cellulase production from bacteria isolated from soil. Int Scholarly Res notices ; 985685:1-7.

13. Pingili M, Marla SR, Raparla R, Vanga S. Isolation and screening of lignocellulose degrading fungi from degraded Fruit Litter. Int J Curr Microbiol App Sci ;6(12):2200-6

14. Arora DS, Chander M, Gill PK. Involvement of lignin peroxidase, manganese peroxidase and laccase in degradation and selective ligninolysis of wheat straw. Int Biodeterior Biodegr 2002;50:115-20.

15. Arora DS, Gill PK. Comparision of two assay procedures for lignin peroxidase. Enzyme Microb Technol 2001;28(7-8):602-5.

16. Michael JB, Peter B, Kaisa P. Interlaboratory testing of methods for assay of xylanase activity. J Biotechnol 1992;23(3):257-70.

17. Ghose TK. Measurement of cellulase activities. Pure Appl Chem; 59(2):257-68

18. Datta R. Acidogenic fermentation of lignocellulose acid yield and conversion of components. Biotechnol Bioeng 1981;23:2167-70.

19. Sharma RK, Arora DS Biodegradation of paddy straw obtained from different geographic locations by means of Phlebia spp. for animal feed. Biodegradation 2011;22:143-52.

20. Asses N, Ayed L, Hkiri N, Hamdi M. Congored decolorisation and detoxification by Aspergillus niger: removal mechanisms and dye degradation pathway. BioMed Res Int 2018;3049686:9.

21. Robinson T, Singh D, Nigam P. Solid state fermentation: a promising microbial technology for secondary metabolite production. Appl Microbiol Biot 2001;55:284-9.
22. Ayeni AO, Adeeyo OA, Oresegun OM, Oladimeji TE. Compositional analysis of lignocellulosic materials: evaluation of an economically viable method suitable for woody and non-woody biomass. Am J Eng Res ;4(4):14-9.

23. Kang SW, Park YS, Hong SI, Kim SW. Production of cellulases and hemicellulases by aspergillus niger KK2 from lignocellulosic biomass. Bioresour Technol ;91:153-6.

24. Coffman AM, Li Q, Ju LK. Effect of natural and pretreated soybean Hulls on enzyme production by Trichoderma reesei. J Am Oil Chem Soc 2014;91:1331-8.

25. Jampala P, Tadikamalla S, Preethi M, Ramanujam S, Uppuluri KB. Concurrent production of cellulose and xylanase from Trichoderma reesei NCIM 1186: enhancement of production by desirability-based multi-objective method. Biotech 2017;7:14.

26. Mrudula S, Murugammal R. Production of cellulase by Aspergillus niger under submerged and solid state fermentation using coir waste as substrate. Braz J Microbiol 2011;42:1119-27.

27. Chandra MS, Vishwanath B, Reddy BR. Cellulolytic enzymes on lignocellulosic substrates in solid state fermentation by Aspergillus niger. Indian J Microbiol 2007;47:323-8.

28. Díaz GV, Coniglio RO, Velazquez JE, Zapata PD, Villalba L, Fonseca MI. Adding value to lignocellulosic wastes via their use for endoxylanase production by Aspergillus fungi. Mycologia 2019;111:2, 195-205.

29. Viniegra G, Favela E, Aguilar C, Romero S, Diaz G, Augur C Advantages of fungal enzyme production in solid state over liquid fermentation systems. Biochem Eng J ;13(2-3):157-67.

30. Palmieri , Cennamo G, Sannia G. Remazol Brilliant Blue R decolorisation by the fungus Pleurotus Ostreatus and its oxidative enzymatic system. Enzyme Microb Tech 2005;36:17-24.

How to cite this article:

Mamatha P, Shailaja RM, Ramakrishna R. Albizia lebbeck fruit pods as a substrate for the production of lignocellulolytic enzymes by Aspergillus niger. J Appl Biol Biotech 2020;8(03):076-080. DOI: 10.7324/JABB.2020.803014 